\title{
Functional Analyses of Two Cellular Binding Domains of Bovine Lactadherin ${ }^{\dagger}$
}

\author{
Mikkel H. Andersen, Helle Graversen, Sergey N. Fedosov, Torben E. Petersen, *, ${ }^{\ddagger}$ and Jan T. Rasmussen \\ Protein Chemistry Laboratory, Department of Molecular and Structural Biology, University of Aarhus, Science Park, \\ Gustav Wieds Vej 10C, 8000 Aarhus C, Denmark
}

Received September 23, 1999; Revised Manuscript Received January 31, 2000

\begin{abstract}
The glycoprotein bovine lactadherin (formerly known as PAS-6/7) comprises two EGF-like domains and two C-like domains found in blood clotting factors V and VIII. Bovine lactadherin binds to $\alpha_{v} \beta_{5}$ integrin in an RGD-dependent manner and also to phospholipids, especially phosphatidyl serine. To define and characterize these bindings the interactions between lactadherin and different mammalian cell types were investigated. Using recombinant forms of bovine lactadherin, the human breast carcinomas MCF-7 cells expressing the $\alpha_{\mathrm{v}} \beta_{5}$ integrin receptor were shown to bind specifically to RGD containing lactadherin but not to a mutated RGE lactadherin. A monoclonal antibody against the $\alpha_{v} \beta_{5}$ integrin receptor and a synthetic RGD-containing peptide inhibited the adhesion of MCF-7 cells to lactadherin. Green monkey kidney MA-104 cells, also expressing the $\alpha_{v} \beta_{3}$ together with the $\alpha_{\mathrm{v}} \beta_{5}$ integrin, showed binding to bovine lactadherin via both integrins. To investigate the interaction of lipid with lactadherin two fragments were expressed corresponding to the $\mathrm{C} 1 \mathrm{C} 2$ domains and the $\mathrm{C} 2$ domain. Both fragments bound to phosphatidyl serine in a concentration-dependent manner with an affinity similar to native lactadherin $\left(K_{\mathrm{d}}=1.8 \mathrm{nM}\right)$. A peptide corresponding to the C-terminal part of the $\mathrm{C} 2$ domain inhibited the binding of lactadherin to phospholipid in a concentration-dependent manner, and finally it was shown that lactadherin mediates binding between artificial phosphatidyl serine membranes and MCF-7 cells. Taken together these results show that lactadherin can act as link between two surfaces by binding to integrin receptors through its $\mathrm{N}$-terminus and to phospholipids through its $\mathrm{C}$-terminus.
\end{abstract}

The bovine glycoprotein lactadherin is an abundant peripheral protein associated with the milk fat globule membrane but is also found in a wide range of tissues and is present in several body fluids $(1,2)$. Lactadherin consists of two N-terminal EGF-like domains followed by two repeated $\mathrm{C}$ domains with homology to the $\mathrm{C} 1$ and $\mathrm{C} 2$ domains of blood clotting factor $\mathrm{V}$ and factor VIII. Two glycosylation variants of the bovine protein exist (formerly known as PAS-6 and PAS-7) (3). Orthologous proteins have been characterized in mouse (MFG-E8, 4), rat (rAGS, 5), pig (P47, 6), and human (BA46 or lactadherin, 7), and several splice variants have been described $(3,8)$. Moreover, a second gene encoding a lactadherin-like protein called Del1 has been identified in mouse, but this protein is only expressed in the embryo endothelium for a short period $(9$, $10)$.

The second EGF domain of bovine lactadherin contains an Arg-Gly-Asp (RGD) $)^{1}$ cell adhesion sequence motif recognized by integrin receptors $(3,7)$. The integrins form a group of heterodimeric divalent cation-dependent cell surface receptors which facilitate cell adhesion to extracellular matrix proteins and cell-cell adhesion. The family consists of over 20 integrins composed of $\alpha$ and $\beta$ subunits

$\doteqdot$ This work is part of the FØTEK program supported by the Danish Dairy Research Foundation (Danish Dairy Board) and the Danish Government.

Tel: +45 89425094. Fax: +45 86136597. E-mail: tep@mbio.aau.dk.

${ }^{1}$ Abbreviations and textual footnotes: BSA, bovine serum albumin; DMEM, Dulbecco's modified Eagle's medium; PBS, phosphatebuffered saline; RGD, Arg-Gly-Asp; TBS, tris-buffered saline. and is highly conserved across species. Ligands to integrin receptors are mainly extracellular matrix proteins such as fibronectin and collagen. Binding the ligand may result in changes in cell life such as adhesion, differentiation, proliferation, and death of cells (11). The RGD motif in lactadherin is located at the turn of the B-loop in the EGF domain and is thereby likely to be exposed to the surroundings. Moreover, the sequence motif in lactadherin is conserved in all species. Subsequently, lactadherin proved to be an integrin receptor ligand, since affinity chromatography against bovine lactadherin purified the $\alpha_{\mathrm{v}} \beta_{5}$ integrin receptor (2). Likewise, human lactadherin and mouse Del1 have been demonstrated to interact with endothelial cells expressing the $\alpha_{v} \beta_{3}$ integrin $(9,12)$. In addition to the association with integrin, lactadherin has the ability to bind cell surfaces directly; e.g., bovine and human lactadherin have been shown to bind anionic phospholipid $(2,13)$. Due to the homology with regions in blood clotting factor V and factor VIII, this binding is assumed to be associated with the $\mathrm{C}$-like domains in lactadherin $(14,15)$.

Little is known about the physiological function of lactadherin, and it remains to be confirmed whether it binds integrin receptors and the lipid surface of the same cells. On the other hand, it seems likely that the function is of a more general character, as lactadherin is widely expressed $(2,5,6,16)$. In pig, it has been suggested that lactadherin could be involved in oocyte/gamete interactions, since considerable amounts could be purified from zone pellucidae (6). Rat lactadherin was identified as an $O$-acetyl ganglioside synthase, since transfection of 9-O-acetyl ganglioside nega- 


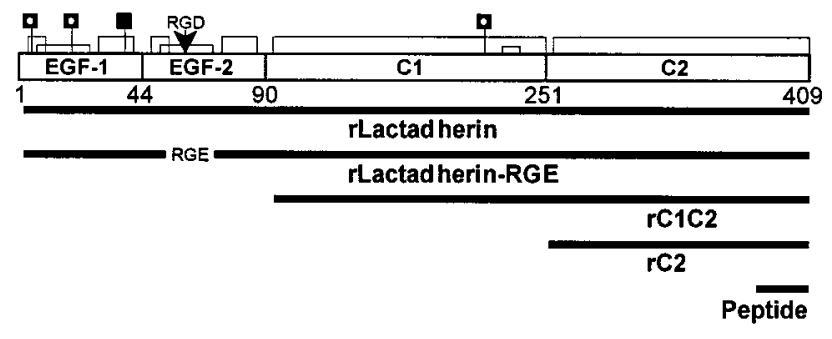

FIGURE 1: Schematic representation of bovine lactadherin and expressed fragments. Carbohydrate sites are marked with $\mathbf{\square}$ for shared glycosylation and with $\mathbf{D}$ for differential glycosylation (3). The position of the RGD motif is indicated, and disulfide bridges are shown with lines. The Asp69 to glutamic acid point mutation in rLactadherin-RGE is indicated.

tive cells with a mammalian expression cDNA library, followed by selection of $9-O$-acetyl ganglioside positive cells, resulted in the isolation of the lactadherin encoding cDNA (5). However, the function as a synthase remains to be confirmed. Human lactadherin has drawn much attention in relation to breast cancer, where it is being tested as a prognostic marker (17). It has also proved to be an antiviral protein as it can inhibit infection of MA-104 cells by rotavirus (13). This effect is probably based on the carbohydrates linked to the protein (18). Recently, a fragment called medin from human lactadherin has been characterized as an amyloid deposit constituent found around small vessels entering the aortic wall (19). Finally, Del1 has an effect on the angiogenesis of blood vessels in the developing embryo $(9,10)$. In the present work we have used recombinant forms or fragments of bovine lactadherin in order to pursue the role of specific regions in cell interactions.

\section{EXPERIMENTAL PROCEDURES}

Antibodies and Peptides. Blocking monoclonal antibodies against human $\alpha_{\mathrm{v}} \beta_{5}\left(\mathrm{P} 1 \mathrm{~F} 6, \mathrm{IgG}_{1}\right)$ and $\alpha_{\mathrm{v}} \beta_{3}\left(\mathrm{LM} 609, \mathrm{IgG}_{1}\right)$ integrin receptors were purchased from Chemicon. Monoclonal control antibodies to initiation factor $2 \beta(2 \mathrm{CE} 5,1 \mathrm{DB} 2$, both $\mathrm{IgG}_{1}$ ) were a kind gift from Dr. H. U. Sperling-Petersen, University of Aarhus. Peptides interfering with integrinligand and lactadherin-lipid interactions were synthesized by Schafer-N, Copenhagen, Denmark (SHRGDVF, RGD peptide hereinafter), ARFVRIQPVAWHNRITLRVELL (membrane peptide hereinafter), or purchased from Bachem, Switzerland (GRGESP, RGE peptide hereinafter).

Protein Expression and Purification. Methanol-inducible yeast Pichia pastoris (Invitrogen, Carlsbad, CA) was used to express recombinant protein constructions (Figure 1). Using PCR with primers PCR1 and PCR2, a cDNA encoding full-length bovine lactadherin (3) was cloned into the pPIC9K expression vector. The $\mathrm{N}$-terminus was reverted to the original using primer MUT1 and the Chameleon site-directed mutagenesis kit (Stratagene, La Jolla, CA). From this construct truncated lactadherin $\mathrm{C} 1 \mathrm{C} 2$ and $\mathrm{C} 2$ domain versions were made ( $\mathrm{rC} 1 \mathrm{C} 2$ and $\mathrm{rC} 2$ ) by introducing restriction sites with primers MUT2 and MUT3 by site-directed mutagenesis. Likewise, the mutation of Asp69 to glutamic acid was done using MUT4 (rLactadherin-RGE). Primers used: PCR1, 5'TCGCCTACGTAGGTGACTTCTGTGACTCCA; PCR2, 5'CCTAAGAATTCGGGATGGCTTGAGGACTGG; MUT1, 5'-GAGAAAAGAGAGGCTGAAGCTTTCTCCGGTGACTTCTGTGAC; MUT2, 5'-GGATACGTGGGCATCCAC-
TACGTAACCACCTGCACCTC; MUT3, 5'-GGCTGTGAGTAGTACGTATGCACTGA; MUT4, 5'-CCCACCGAGGGGAAGTCTTCATCCAG. Obtained constructions were subjected to sequencing analyses. The SMD1168 yeast strain (Invitrogen, Carlsbad, CA) was transformed by electroporation and screened for expression by western blotting. Promising clones were selected for large scale expressions in buffered methanol-complex medium. Before methanol induction high cell density was obtained in buffered glycerolcomplex medium. After incubation with methanol, the medium was recovered by centrifugation $(16000 \mathrm{~g}, 10 \mathrm{~min})$ and precipitated with $80 \%(\mathrm{w} / \mathrm{v})\left(\mathrm{NH}_{4}\right)_{2} \mathrm{SO}_{4}$. The precipitate was resuspended in and dialyzed against $50 \mathrm{mM}$ Tris- $\mathrm{HCl}$, pH 7.4, $150 \mathrm{mM} \mathrm{NaCl}$ overnight. Affinity chromatography on a $1.5 \times 10 \mathrm{~cm}$ agarose column (Mini-Leak Medium, Kem-En-Tec, Copenhagen, Denmark) coupled with $30 \mathrm{mg}$ of anti-lactadherin $\mathrm{IgG}$ was used to purify all recombinant constructs. The dialyzed medium was applied onto the column equilibrated in $50 \mathrm{mM}$ Tris- $\mathrm{HCl}, \mathrm{pH} 7.4,150 \mathrm{mM}$ $\mathrm{NaCl}(10 \mathrm{~mL} / \mathrm{h})$, which was then washed with 10 column volume $50 \mathrm{mM}$ Tris- $\mathrm{HCl}, \mathrm{pH} 7.4,0.5 \mathrm{M} \mathrm{NaCl}$. By the decrease of $\mathrm{pH}$ with $100 \mathrm{mM}$ glycine at $\mathrm{pH} 2.35$, bound protein was eluted and $\mathrm{pH}$ in fractions was adjusted to 8.0 with $3 \mathrm{M}$ Tris- $\mathrm{HCl}, \mathrm{pH}$ 8.0. Eluted protein was dialyzed against $50 \mathrm{mM} \mathrm{NH} \mathrm{HCO}_{3}, \mathrm{pH} 7.8$, and concentrated on an Amicon cell followed by determination of the N-terminal amino acid sequence and amino acids analysis. Native lactadherin was purified from bovine milk as previously described (3).

Cell Adhesion Assay. Tissue culture cluster plates (96well, Costar Corp., Cambridge, MA) were coated overnight at $4{ }^{\circ} \mathrm{C}$ with proteins diluted in phosphate-buffered saline (PBS, 7 mM Na $2 \mathrm{HPO}_{4}, 3 \mathrm{mM} \mathrm{NaH} \mathrm{PO}_{4}, \mathrm{pH} 7.3,130 \mathrm{mM}$ $\mathrm{NaCl}$ ) to the appropriate concentrations. Controls contained either bovine serum albumin (BSA) in PBS buffer or just PBS buffer. The next day plates were washed 3 times with PBS buffer and blocked with $200 \mu \mathrm{L}$ of $10 \mathrm{mg} / \mathrm{mL}$ BSA in PBS buffer. Human breast carcinomas MCF-7 cells (ATCC, HTB-22) and green monkey kidney MA-104 cells (ATCC, CRL-2378) were grown to near confluence in Dulbecco's modified Eagle's medium (DMEM) supplemented with $10 \%$ fetal bovine serum, L-glutamine, penicillin, and streptomycin (BioWhittaker, Walkersville, MD). Cells were detached with trypsin in PBS buffer/EDTA and washed twice with DMEM with glutamine, penicillin, streptomycin, and $10 \mathrm{mg} / \mathrm{mL}$ BSA before resuspending in the same medium. Cells were plated at 40000 cells/well and allowed to adhere for $1 \mathrm{~h}$ at $37^{\circ} \mathrm{C}$. If added, $\operatorname{IgG}(50 \mu \mathrm{g} / \mathrm{mL})$ or peptide $(0.2 \mathrm{mM})$ was incubated with cells in suspension for $1 \mathrm{~h}$ at $37^{\circ} \mathrm{C}$ before plated. Wells were then washed 3 times in PBS buffer. Detection of adherent cells was performed essentially as described by Lewis et al. (20). Cells were incubated with $100 \mu \mathrm{L}$ of 50 $\mathrm{mM}$ sodium citrate, $\mathrm{pH} 5.0,0.4 \%$ Triton $\mathrm{X}-100$, and $3 \mathrm{mg} /$ $\mathrm{mL}$ nitrophenyl phosphate (Sigma Chemical Co., St. Louis, MO) for $2 \mathrm{~h}$ at $37^{\circ} \mathrm{C}$ with shaking. After addition of $25 \mu \mathrm{L}$ of $1 \mathrm{M} \mathrm{NaOH}$ a sample of $50 \mu \mathrm{L}$ was added to $50 \mu \mathrm{L}$ of water in a microtiter plate (Nunc, Roskilde, Denmark), and the absorbance at $405 \mathrm{~nm}$ was determined in a Bio-Tek EL 311s Autoreader (Bio-Tek, Winooski, VT). A calibration experiment of cells in suspension showed that absorbance values were directly proportional to cell number in the range from 500 to 50000 cells (MCF-7: 100\% adhesion 35000 
cells; MA-104: 100\% adhesion $~ 18000$ cells). Unspecific adhesion to BSA was subtracted from results, and all experiments were performed at least three times, all yielding representative results.

A modification of the above method was used when testing lactadherin as a cell linker protein. Phospholipid solutions of $3 \mu \mathrm{g} / \mathrm{mL}$ in methanol $(100 \mu \mathrm{L})$ were plated and dried at room temperature, before blocked with $10 \mathrm{mg} / \mathrm{mL}$ BSA in PBS buffer (200 $\mu \mathrm{L}$ per well). Lactadherin was diluted to the appropriate concentration in $10 \mathrm{mg} / \mathrm{mL}$ BSA in PBS buffer $(100 \mu \mathrm{L} /$ well $)$ and incubated for $2 \mathrm{~h}$ at $37^{\circ} \mathrm{C}$. Plates were then washed in PBS buffer, and cells were added to the wells. As control, lactadherin added to PS negative and also to BSA blocked wells showed no MCF-7 adhesion (data not shown). Detection was performed as described above.

Lipid Binding Using Solid-Phase ELISA. The solid-phase ELISA for lactadherin, $\mathrm{rC} 1 \mathrm{C} 2$, and $\mathrm{rC} 2$ binding to phospholipid was performed as described (21). Binding to L- $\alpha$ phosphatidyl-L-serine (PS) (Sigma Chemical Co., St. Louis, MO) was tested by adding $100 \mu \mathrm{L}$ of PS solution $(3 \mu \mathrm{g} / \mathrm{mL}$ in methanol) to microtiter plates and allowed to dry at room temperature. All subsequent steps were performed at $37^{\circ} \mathrm{C}$, and plates were washed 3 times between steps with Trisbuffered saline (TBS) and $0.05 \%$ Tween-20. The plates were blocked with $200 \mu \mathrm{L}$ of TBS with $0.05 \%$ (w/v) gelatine (blocking buffer). Proteins were diluted to the appropriate concentration in blocking buffer, and $100 \mu \mathrm{L}$ was added per well. When inhibitory lactadherin C-terminal peptide (Ala386Leu407) was added, it was mixed with appropriate protein prior to the addition to the well. The plates were then incubated with $100 \mu \mathrm{L}$ of polyclonal rabbit antibody against lactadherin diluted in blocking buffer $(0.5 \mu \mathrm{g} / \mathrm{mL})$. Finally, plates were incubated with $100 \mu \mathrm{L}$ of peroxidase-labeled swine antirabbit antibodies diluted 1:2000 in blocking buffer. Bound peroxidase activity was measured by adding $100 \mu \mathrm{L}$ of 1,2-phenyleneamine dihydrochloride (DAKO, Glostrup, Denmark) dissolved in $12 \mathrm{~mL}$ of $0.1 \mathrm{M}$ sodium citrate, $\mathrm{pH}$ 5.0. Reactions were stopped with $100 \mu \mathrm{L}$ of $2 \mathrm{M} \mathrm{H}_{2} \mathrm{SO}_{4}$ after 4 min incubation at room temperature, and the absorbance at $490 \mathrm{~nm}$ was measured. Protein concentration in the protein stocks was determined by amino acid analysis.

\section{RESULTS}

Lactadherin Facilitates Human MCF-7 Cell Adhesion. Bovine and human lactadherin has been shown to bind $\alpha_{\mathrm{v}} \beta_{5}$ and $\alpha_{\mathrm{v}} \beta_{3}$ integrins, respectively $(2,12)$, which prompted us to investigate the integrin association further. Interaction of integrin receptors with bovine lactadherin was surveyed by a cell adhesion assay performed in microtiter plates. Recently, it was shown that the human breast cancer cell line MCF-7 expresses the $\alpha_{\mathrm{v}} \beta_{5}$ integrin but not the $\alpha_{\mathrm{v}} \beta_{3}$ integrin receptor (22). Therefore this cell line was chosen as target for lactadherin-mediated adhesion. Purified lactadherin was used to coat wells of microtiter plates, and cells were allowed to adhere to the coated wells for $1 \mathrm{~h}$. After incubation the number of adherent cells was assayed using a colorimetric method. The assay proved versatile, since lactadherin mediated binding of MCF-7 cells in a concentration-dependent manner (Figure 2A). Maximal MCF-7 binding was obtained when the wells were coated with lactadherin at a concentration of $20-30 \mathrm{nM}$. Thus, for the following experiments
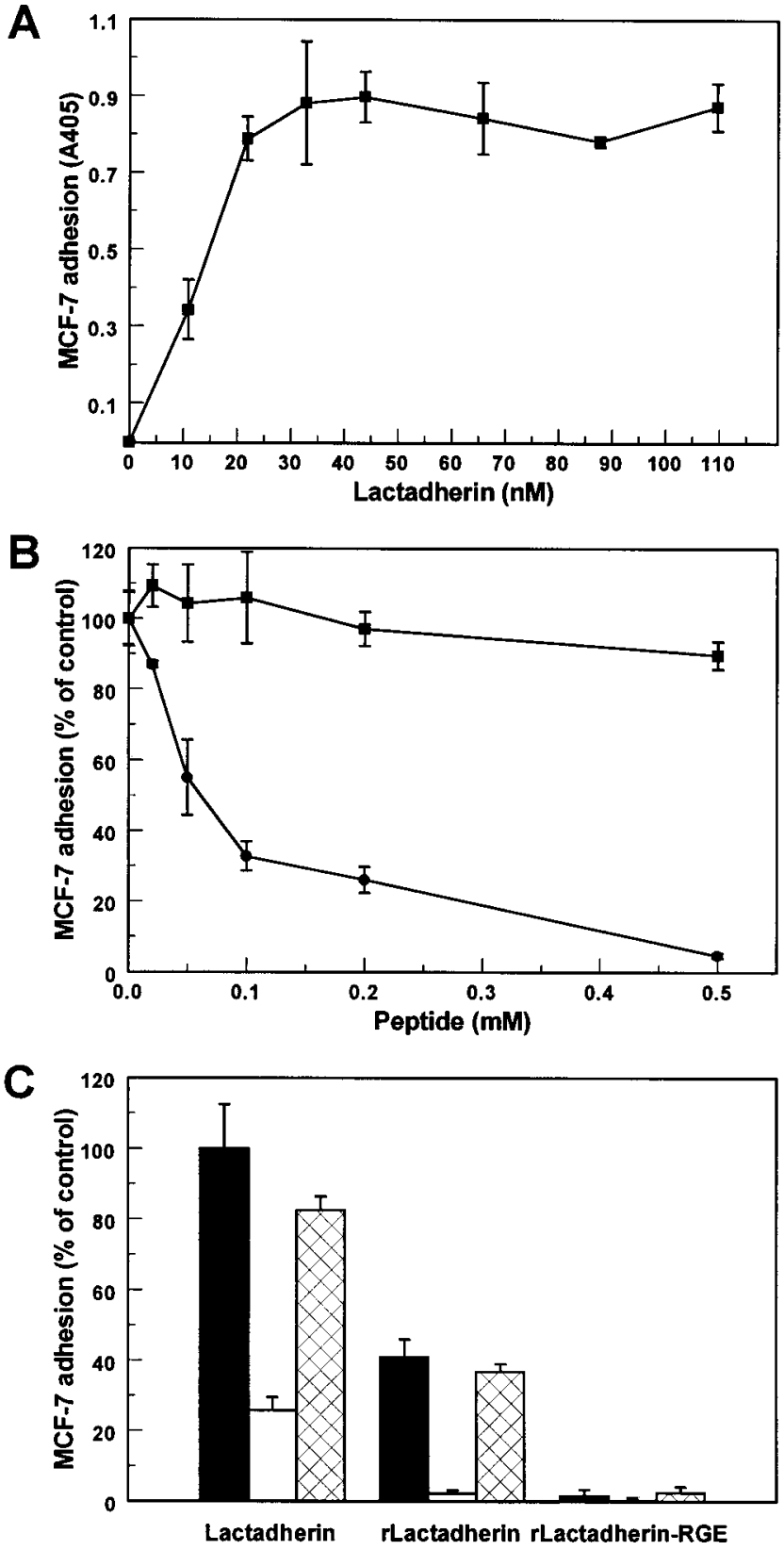

FIGURE 2: Cell adhesion assays of MCF-7 cells to lactadherin. (A) Wells of microtiter plates were coated with bovine lactadherin in various amounts purified from bovine milk. After the blocking of wells with PBS-buffer/1\% BSA $100 \mu \mathrm{L}$ of cells suspended in DMEM $/ 1 \%$ BSA (40 000/well) was added and cells were allowed to adhere for $1 \mathrm{~h}$ at $37^{\circ} \mathrm{C}$. After the washing of wells with PBS buffer, bound cells were quantified with a colorimetric endogenous cellular phosphatase assay. Control wells were coated with BSA. (B) Inhibition of MCF-7 cell attachment to lactadherin $(2 \mu \mathrm{g} / \mathrm{mL}$ coating) by integrin blocking peptides. Cells in suspension were

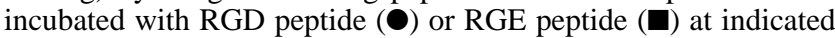
concentrations before addition to wells. (C) MCF-7 cell attachment to lactadherin, recombinant rLactadherin, and rLactadherin-RGE $(2 \mu \mathrm{g} / \mathrm{mL})$. Cells in suspension were incubated without blocking peptide (solid bars), $0.2 \mathrm{mM}$ RGD peptide (open bars), or $0.2 \mathrm{mM}$ RGE peptide (crosshatched bars). For all experiments data are expressed as mean \pm standard deviation $(n=4)$.

coating was performed with $43 \mathrm{nM}$ solutions. When cells were inspected under light microscope, they adhered and spread on lactadherin and displayed normal cell morphology. This was not observed when plated on BSA or if EDTA was added (data not shown). 
RGD Motif in Lactadherin Is Responsible for Cell Adhesion. To investigate whether MCF-7 binding to lactadherin was solely dependent on the RGD cell adhesion motif, a 7 amino acid synthetic peptide comprising the RGD region in lactadherin was used in peptide inhibiting studies. As the peptide concentration was increased, the number of cells attached decreased as expected (Figure 2B). With $10 \mu \mathrm{M}$ peptide significant inhibition was observed, at $100 \mu \mathrm{M}$ binding was reduced to approximately $30 \%$, and finally at $500 \mu \mathrm{M}$ RGD peptide no MCF-7 adhesion was observed. As control, added RGE peptide had no effect even in high concentrations $(500 \mu \mathrm{M})$.

Recombinant rLactadherin but Not rLactadherin-RGE Supported MCF-7 Cell Adhesion. To supplement the peptide inhibiting studies site-directed mutagenesis was used to generate two recombinant lactadherin constructs in Pichia pastoris yeast. According to the peptide inhibiting experiments, mutating Asp65 to Glu (rLactadherin-RGE) should abolish the integrin binding. As shown in Figure 2C, rLactadherin-RGE displayed no binding site for the MCF-7 cells whereas the controls, lactadherin and rLactadherin, were both able to adhere to the cells. Moreover, adding RGD peptide together with the cells inhibited the binding to both lactadherin and rLactadherin, but no significant effect was seen with the RGE control peptide (Figure 2C). The observed reduced binding ability of rLactadherin, when compared to purified native lactadherin, may be due to incorrect folding in the EGF tandem repeat, since we were unable to obtain correct folding during attempts to express this part alone (data not shown). This was subsequently confirmed by limited proteolysis followed by peptide mapping of lactadherin, rLactadherin, and rLactadherin-RGE (not shown).

Specific Inhibition of Cell Adhesion to Lactadherin by Monoclonal Antibody to $\alpha_{v} \beta_{5}$ Integrin Receptor. To verify that the $\alpha_{\mathrm{v}} \beta_{5}$ integrin receptor was involved in MCF-7 cell adhesion to lactadherin, the effect of a monoclonal antibody P1F6 able to inhibit ligand binding to the $\alpha_{\mathrm{v}} \beta_{5}$ integrin was tested. This was performed by preincubating MCF-7 cells with P1F6 for $1 \mathrm{~h}$ prior to analysis for adhesion to lactadherin. The antibody reduced the MCF-7 adhesion to lactadherin to less than 20\% (Figure 3A). Two control monoclonal antibodies to an intracellular protein had no effect on the adhesion to lactadherin when added in the same concentration as P1F6.

Bovine Lactadherin Binds both the $\alpha_{v} \beta_{3}$ and $\alpha_{v} \beta_{5}$ Integrin Receptors. Since human lactadherin has been shown to bind the $\alpha_{v} \beta_{3}$ integrin receptor, green monkey kidney MA-104 cells expressing functionally active $\alpha_{\mathrm{v}} \beta_{3}$ integrin receptor (12) were investigated for the ability to adhere to bovine lactadherin. Like MCF-7 cells, the MA-104 cells bound to lactadherin as a function of the amount of protein in the well reaching a maximum when $20-30 \mathrm{nM}$ was used for coating. Furthermore, MA-104 cells were unable to adhere to rLactadherin-RGE (data not shown). To identify which receptor is involved in binding, the effects of two monoclonal antibodies were assayed. The antibody LM609 inhibiting the $\alpha_{\mathrm{v}} \beta_{3}$ integrin reduced MA-104 cell adhesion to lactadherin to under $20 \%$, whereas the $\alpha_{\mathrm{v}} \beta_{5}$ specific antibody P1F6 inhibited adhesion to about $50 \%$ of the control (Figure 3B). Thus, bovine lactadherin is a ligand for both the $\alpha_{\mathrm{v}} \beta_{3}$ and $\alpha_{\mathrm{v}} \beta_{5}$ integrin receptors, when assayed against the human receptors.
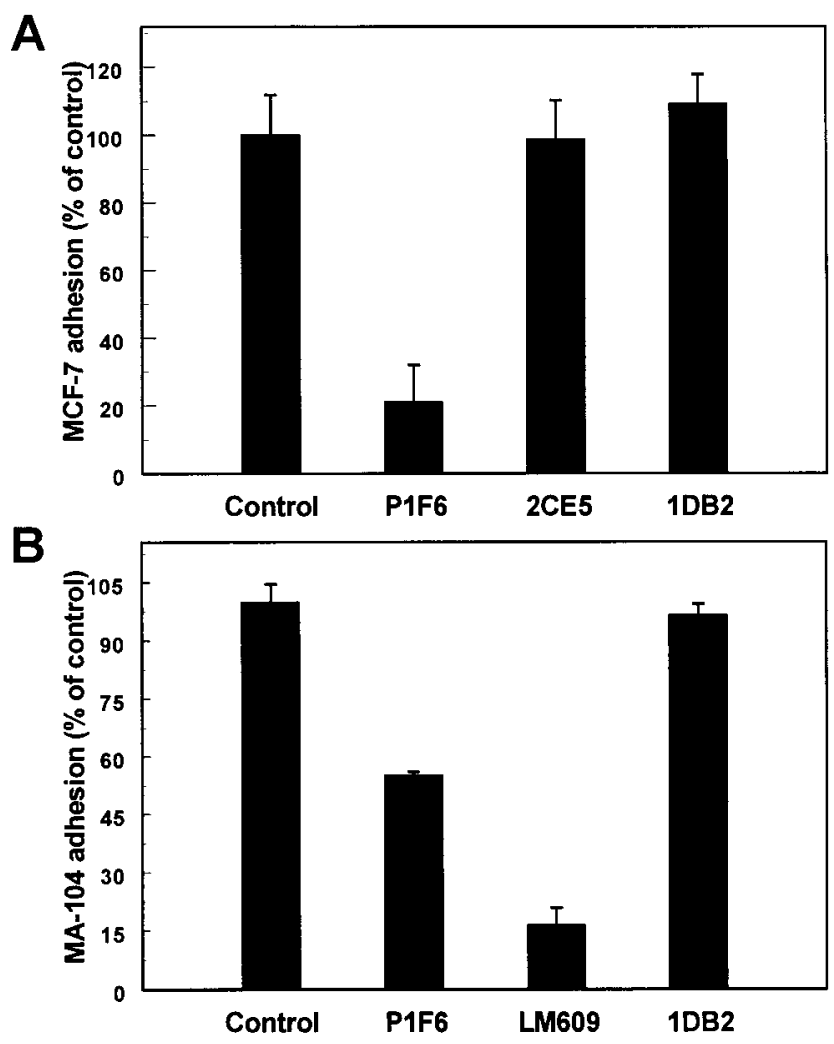

FIGURE 3: Inhibition of adhesion by monoclonal antibodies to integrins. (A) Inhibition of MCF-7 cell attachment to bovine lactadherin by monoclonal antibody to $\alpha_{\mathrm{v}} \beta_{5}$ integrin receptor. Wells were coated overnight with $2 \mu \mathrm{g} / \mathrm{mL}$ lactadherin protein and blocked with PBS buffer/1\% BSA. Cells in suspension were incubated without antibody, $50 \mu \mathrm{g} / \mathrm{mL}$ integrin blocking monoclonal P1F6 antibody, or $50 \mu \mathrm{g} / \mathrm{mL}$ control monoclonal antibody (2CE5, 1DB2) for $1 \mathrm{~h}$ at $37^{\circ} \mathrm{C}$ before addition to wells. (B) Inhibition of MA104 cell attachment to lactadherin $(2 \mu \mathrm{g} / \mathrm{mL}$ coating $)$ by monoclonal antibodies to integrin receptors. Cells in suspension were incubated without any addition, with $50 \mu \mathrm{g} / \mathrm{mL}$ integrin blocking monoclonal antibody (P1F6 to $\alpha_{v} \beta_{5} ;$ LM609 to $\alpha_{\mathrm{v}} \beta_{3}$ ), or $50 \mu \mathrm{g} / \mathrm{mL}$ monoclonal control antibody (1DB2). Data are expressed as mean \pm standard deviation $(n=4)$.

Phospholipid Interaction Is Mediated by a C-Terminal Segment of Lactadherin. Several investigators have shown that the extreme $\mathrm{C}$-terminus of the $\mathrm{C} 2$ domain of the blood clotting factor $\mathrm{V}$ and factor VIII is involved in phospholipid binding $(15,23,24)$. In analogy with that we and others have demonstrated that lactadherin binds to phospholipids, preferentially phosphatidylserine (PS) $(2,13)$. To further investigate this, two truncated fragments comprising the $\mathrm{C} 1 \mathrm{C} 2$ and $\mathrm{C} 2$-like domains of lactadherin $(\mathrm{rC} 1 \mathrm{C} 2$ and $\mathrm{rC} 2)$ were expressed in Pichia pastoris and assayed for phospholipid association. Various amounts of lactadherin, $\mathrm{rC} 1 \mathrm{C} 2$, and $\mathrm{rC} 2$ were added to PS-coated microtiter plates and quantified with a polyclonal antibody against lactadherin. All three proteins bound to PS in a concentration-dependent manner (Figure 4). The fragments $\mathrm{rC} 1 \mathrm{C} 2$ and $\mathrm{rC} 2$ gave a weaker response, possibly due to loss of antigenic regions. Assuming a simple one site binding model for the lactadherin association with the artificial PS membrane, a fit to the binding curves gave the following $K_{\mathrm{d}}$ values: lactadherin, $1.8 \mathrm{nM} ; \mathrm{rC} 2,2.0 \mathrm{nM}$; $\mathrm{rC} 1 \mathrm{C} 2,4.9 \mathrm{nM}$. These values are within the same order of magnitude as those determined for factor $\mathrm{V}$ and factor VIII using other methods $(14,25)$. The involvement of the extreme C-terminus of lactadherin in PS binding was 


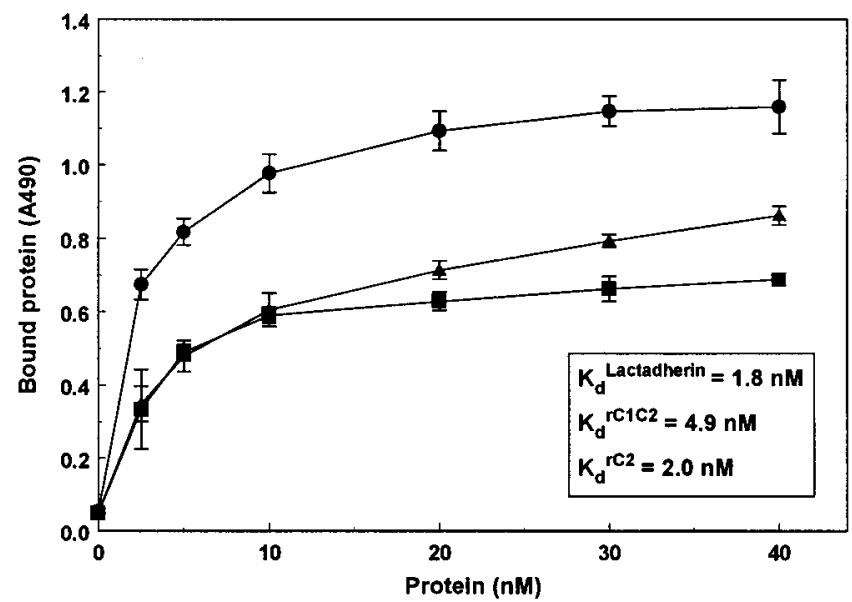

FIGURE 4: Lactadherin, rC1C2, and rC2 affinity for PS. Wells were coated with PS and blocked with gelatine buffer. After washing, wells were incubated with various amounts of lactadherin (O), rC1C2 ( $\mathbf{\Delta})$, or $\mathrm{rC} 2(\boldsymbol{\square})$. Binding of lactadherin was monitored with a polyclonal antibody against lactadherin. Uncoated wells treated with protein showed no binding. Data are expressed as mean \pm standard deviation $(n=4)$.

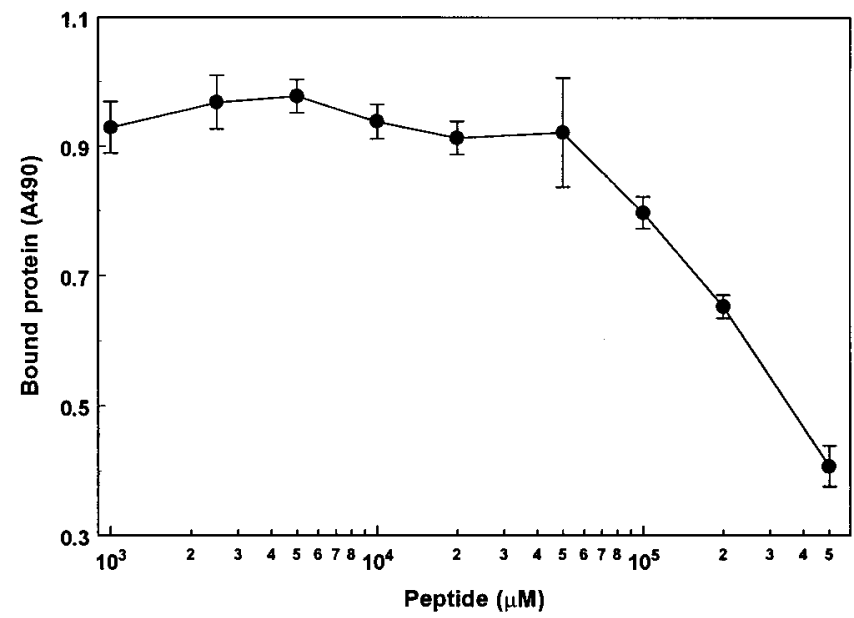

FIGURE 5: Inhibition of lactadherin binding to PS by synthetic membrane peptide comprising the extreme C-terminal of lactadherin. Peptide was added in various concentrations together with lactadherin to PS-coated wells and allowed to equilibrate for $4 \mathrm{~h}$ at $37^{\circ} \mathrm{C}$. Binding of lactadherin was monitored with a polyclonal antibody against lactadherin. Data are expressed as mean \pm standard deviation $(n=4)$

investigated by displacement experiments using a synthetic 22 amino acid peptide comprising this region. Upon PScoating it was seen that the binding ability of a fixed amount of lactadherin $(20 \mathrm{nM})$ was reduced as a result of increasing amounts of the competing peptide (Figure 5). Thus, the result identifies the 22 amino acid C-terminal stretch in lactadherin as at least partly responsible for the PS membrane association of the protein.

MCF-7 Cells Can Adhere to PS-Associated Lactadherin. Finally, to show whether lactadherin bound to PS membranes could support MCF-7 cell adhesion, a modified cell adhesion assay was conducted. Before addition of lactadherin in various concentrations, microtiter plates were coated with PS followed by BSA coating which inhibits any unspecific binding of lactadherin to the plastic. After the cells had been allowed to adhere for $1 \mathrm{~h}$ at $37^{\circ} \mathrm{C}$, the wells were washed and the number of adherent cells was measured by the colorimetric method used above. Cells adhered to PS-

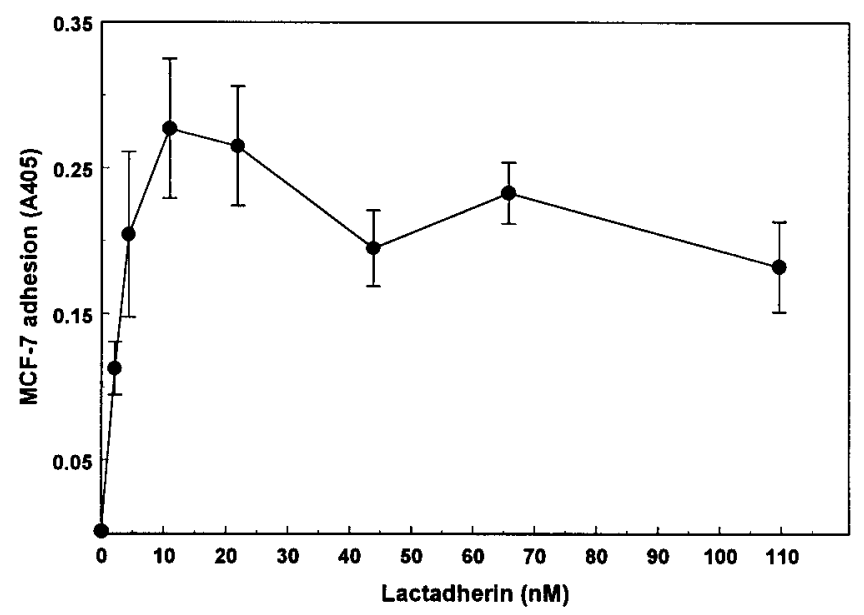

FIGURE 6: Lipid-associated lactadherin supports MCF-7 cell adhesion. Microtiter wells coated with PS were blocked with PBS buffer/1\% BSA prior to incubation with lactadherin at indicated concentrations. Afterward 40000 cells/well were added to PBSbuffer washed wells and cells were allowed to adhere for $1 \mathrm{~h}$ at 37 ${ }^{\circ} \mathrm{C}$. Bound cells were then quantified as described in experimental procedures. Data are expressed as mean \pm standard deviation ( $n$ $=4)$.

associated lactadherin as a function of the increased amounts of protein (Figure 6). The highest level of binding was achieved at $10-20 \mathrm{nM}$ lactadherin, which is close to the maximum lactadherin binding to PS seen in the previously presented lipid assay binding (Figure 4). As control, lactadherin added to PS negative and also to BSA-blocked PS positive wells showed no MCF-7 adhesion (data not shown). This experiment thereby showed that lactadherin can act as a linker between MCF-7 cells and PS-rich membranes.

\section{DISCUSSION}

Several studies have demonstrated that the RGD sequence motif found in lactadherin could be responsible for an in vivo integrin receptor association. This was based on structural data implying that the RGD motif was exposed on the surface of the EGF domain of lactadherin. Purification of the bovine $\alpha_{v} \beta_{5}$ integrin receptor by lactadherin affinity chromatography illustrated a specific interaction between the two proteins (2). In accordance with that, others have shown that human lactadherin and murine Del1 also bind to integrin receptors. However, unlike bovine lactadherin both human lactadherin and Del1 have been assigned as $\alpha_{v} \beta_{3}$ integrin ligands $(9,12)$. An RGD peptide and a monoclonal antibody to the RGD region in human lactadherin were able to inhibit the binding of lactadherin to MA-104 cells (12). Furthermore, the $\alpha_{v} \beta_{3}$ integrin specific antibody LM609 was shown to inhibit MA-104 cell adhesion. The same approach was used in experiments with Del1, and in this case some $\alpha_{v} \beta_{5}$ integrin binding was also seen when human umbilical vein endothelial cells were used (10). The present results demonstrate that bovine lactadherin can function as an effective extracellular matrix for the adhesion of cells containing the $\alpha_{v} \beta_{3}$ and $\alpha_{v} \beta_{5}$ integrin receptors. Expression of the $\alpha_{v} \beta_{3}$ integrin seems to be confined to a smaller number of cell types primarily proliferating endothelial cells (26), whereas the $\alpha_{v} \beta_{5}$ integrin receptor is expressed in a number of different tissues (27, 28 ) and the pattern is similar to that of lactadherin (2).

Numerous studies report the extreme C-terminus of factor VIII to be at least partly responsible for the platelet 
membrane association. The structure of a 22 amino acid long peptide from this region of factor VIII has been determined (24), and from these experiments it was concluded that this peptide was able to form an amphipatic $\alpha$-helix when presented to SDS micelles. We have found that a synthetic peptide comprising the corresponding 22 residues in lactadherin was able to repress the interaction of lactadherin with a PS membrane, and in agreement with this a monoclonal antibody to the same region in human lactadherin was unable to recognize the protein when this was membrane associated (17). However, two recent crystal structures of human factor $\mathrm{V}$ and factor VIII C2 domains showed that the suggested peptide is part of a core $\beta$-sheet structure, and three loops extending from the core are proposed as associating with the membrane $(29,30)$. Thus, the inhibitory mechanism of the C-terminal peptide on lactadherin binding to PS membranes is not obvious.

A 50 residue long peptide has been isolated from aortic medial amyloid and shown to originate from the $\mathrm{C} 2$ domain of lactadherin (19). The peptide, called medin, contained two of the three loops which according to the crystal structure of the $\mathrm{C} 2$ domain of factor $\mathrm{V}$ and factor VIII were involved in the binding to PS. Furthermore, in situ hybridization on sections of aortic media with a lactadherin riboprobe showed that lactadherin was produced locally by aortic smooth muscle cells and by the endothelium of small medial vessels (19). Recently, we investigated the expression of the $\alpha_{v} \beta_{5}$ integrin in bovine lung tissue using an antibody against the receptor and found it expressed in the media of vessel walls (unpublished results), and others have found the $\alpha_{v} \beta_{3}$ integrin receptor expressed in the endothelium of large vessels (31). These findings are in agreement with the detection of a high concentration of lactadherin in bovine heart and lung tissues (2) and put focus on lactadherin in normal and pathological vascular biology.

One should note that in the present experiments lactadherin apparently binds to the tested cells via the RGD motif and not through the lipid binding sequence in the C-terminus. In the lactating mammary gland, lactadherin clearly associates with the apical membrane of the secreting epithelial cells (32). Since we have been unable to detect with western blotting any $\alpha_{v}$ integrin receptor subunit in the fat globule membrane which originate from the epithelial cell membrane (unpublished results), it is likely that lactadherin is bound to this membrane by lipid interaction and not as ligand to an $\alpha_{\mathrm{v}}$ integrin. Factor V and factor VIII circulate in blood and are mainly associated with membranes upon PS exposure (14). Data presented here and earlier reports show that lactadherin binds to membranes in a similar fashion $(2,13)$. However, lactadherin is not present in normal serum, where it could be a potent modulator of the coagulation cascade, yet detectable in serum from breast cancer patients (33). Lactadherin is therefore a potential candidate for mediating cancer-induced clotting defects.

Apoptosis is a major event during embryogenesis, morphogenesis, and normal cell turn over, and the process is important since it prevents the uncontrolled release of intracellular components. Transport of anionic PS to the outer membrane leaflet is an early and widespread event during apoptosis (34). As regards lactadherin, it has been stated that the expression of murine lactadherin is induced 20-fold during the involution of the mammary gland, a major apoptotic event (35). The lactadherin integrin receptors are involved in endocytosis during apoptosis, and the expression of them is induced during the differentiation from the monocyte series $(36,37)$. Since apoptosis-derived bodies display PS on their surface, lactadherin may be important for the macrophage uptake of these bodies. Recently, murine lactadherin was found on dendrite cell derived exosomes, PS displaying small membrane vesicles, and it is suggested that these exosomes are targeted for uptake by other cells via lactadherin-integrin receptor interactions (38). Therefore, a model in which PS-associated lactadherin binds to e.g. macrophage integrin receptors prior to endocytosis may be interesting to pursue.

The presented results show that bovine lactadherin is a specific ligand for the $\alpha_{\mathrm{v}} \beta_{3}$ and $\alpha_{\mathrm{v}} \beta_{5}$ receptors and they are able to support MCF-7 and MA-104 cell adhesion. It is also clear that lactadherin can bind to cell surfaces in a receptorindependent manner. As lactadherin is only likely to bind to PS-enriched membrane surfaces, it is relevant to probe for a function of this protein in relation to apoptosis and endocytotic events involving the integrin receptors. Finally, the in situ tissue distribution of lactadherin and its integrin receptors in a wider number of tissues may give information facilitating the understanding of the physiological function of the protein.

\section{ACKNOWLEDGMENT}

We express our thanks to Marie Kveiborg and Kim Jensen, Department of Molecular and Structural Biology, University of Aarhus, for advice and technical assistance with cells.

\section{REFERENCES}

1. Butler, J. E., Pringnitz, D. J., Martens, C. L., and Crouch, N. (1980) Differentiation 17, 31-40.

2. Andersen, M. H., Berglund, L., Rasmussen, J. T., and Petersen, T. E. (1997) Biochemistry 36, 5441-5446.

3. Hvarregaard, J., Andersen, M. H., Berglund, L., Rasmussen, J. T., and Petersen, T. E. (1996) Eur. J. Biochem. 240, 628636.

4. Stubbs, J. D., Lekutis, C., Singer, K. L., Bui, A., Yuzuki, D., Srinivasan, U., and Parry, G. (1990) Proc. Natl. Acad. Sci. U.S.A. 87, 8417-8421.

5. Ogura, K., Nara, K., Watanabe, Y., Kohno, K., Tai, T., and Sanai, Y. (1996) Biochem. Biophys. Res. Commun. 225, 932938.

6. Ensslin, M., Vogel, T., Calvete, J. J., Thole, H. H., Schmidtke, J., Matsuda, T., and Topfer-Petersen, E. (1998) Biol. Reprod. $58,1057-1064$.

7. Couto, J. R., Taylor, M. R., Godwin, S. G., Ceriani, R. L., and Peterson, J. A. (1996) DNA Cell Biol. 15, 281-286.

8. Oshima, K., Aoki, N., Negi, M., Kishi, M., Kitajima, K., and Matsuda, T. (1999) Biochem. Biophys. Res. Commun. 254, $522-528$.

9. Hidai, C., Zupancic, T., Penta, K., Mikhail, A., Kawana, M., Quertermous, E. E., Aoka, Y., Fukagawa, M., Matsui, Y., Platika, D., Auerbach, R., Hogan, B. L. M., Snodgrass, R., and Quertermous, T. (1998) J. Biol. Chem. 274, 11101-11109.

10. Penta, K., Varner, J. A., Liaw, L., Hidai, C., Schatzman, R., and Quertermous, T. (1999) J. Biol. Chem. 274, 11101-11109.

11. Hynes, R. O. (1992) Cell 69, 11-25.

12. Taylor, M. R., Couto, J. R., Scallan, C. D., Ceriani, R. L., and Peterson, J. A. (1997) DNA Cell Biol. 16, 861-869.

13. Peterson, J. A., Patton, S., and Hamosh, M. (1998) Biol. Neonate 74, 143-162. 
14. Gilbert, G. E., Sims, P. J., Wiedmer, T., Furie, B., Furie, B. C., and Shattil, S. J. (1991) J. Biol. Chem. 15, 17261-17268.

15. Ortel, T. L., Quinn-Allen, M. A., Keller, F. G., Peterson, J. A., Larocca, D., and Kane, W. H. (1994) J. Biol. Chem. 269, $15898-15905$.

16. Couto, J. R., Blank, E. W., Peterson, J. A., and Ceriani, R. L. (1995) Cancer Res. 55, 1717-1722.

17. Peterson, J. A., Couto, J. R., Taylor, M. R., and Ceriani, R. L. (1995) Cancer Res. 55, 5847s-5851s.

18. Yolken, R. H., Peterson, J. A., Vonderfecht, S. L., Fouts, E. T., Midthun, K., and Newburg, D. S. (1992) J. Clin. Invest. 90, 1984-1991.

19. Häggqvist, B., Näslund, J., Sletten, K., Westermark, G. T., Mucchiano, G., Tjernberg, L. O., Nordstedt, C., Engström, U., and Westermark, P. (1999) Proc. Natl. Acad. Sci. U.S.A. 96, 8669-8674.

20. Lewis, J. M., Cheresh, D. A., and Schwartz, M. A. (1996) J. Cell Biol. 134, 1323-1332.

21. Bloom, J. W. (1987) Throm. Res. 48, 439-448.

22. Doerr, M. E., and Jones, J. I. (1996) J. Biol. Chem. 271, $2443-$ 2447.

23. Foster, P. A., Fulcher, C. A., Houghten, R. A., and Zimmerman, T. S. (1990) Blood 10, 1999-2004.

24. Gilbert, G. E., and Baleja, J. D. (1995) Biochemistry 34, 30223031.

25. Saenko, E. L., Scandella, D., Yakhyaev, A. V., and Greco, N. J. (1998) J. Biol. Chem. 43, 27918-27926.

26. Eliceiri, B. P., and Cheresh, D. A. (1999) J. Clin. Invest. 103, 1227-1230.

27. Pasqualini, R., Bodorova, J., Ye, S., and Hemler, M. E. (1993) J. Cell Sci. 105, 101-111.
28. Gui, G. P., Wells, C. A., Browne, P. D., Yeomans, P., Jordan, S., Puddefoot, J. R., Vinson, G. P., and Carpenter, R. (1995) Surgery 117, 102-108.

29. Macedo-Ribeiro, S., Bode, W., Huber, R., Quinn-Allen, M. A., Kim, S. W., Ortel, T. L., Bourenkov, G. P., Bartunik, H. D., Stubbs, M. T., Kane, W. H., and Fuentes-Prior, P. (1999) Nature 402, 434-439.

30. Pratt, K. P., Shen, B. W., Takeshima, K., Davie, E. W., Fujikawa, K., and Stoddard, B. L. (1999) Nature 402, 439442.

31. Damjanovich, L., Albelda, S. M., Mette, S. A., and Buck, C. A. (1992) Am. J. Respir. Cell Mol. Biol. Feb, 197-206.

32. Aoki, N., Kuroda, H., Urabe, M., Taniguchi, Y., Adachi, T., Nakamura, R., and Matsuda, T. (1994) Biochim. Biophys. Acta 1199, 87-95.

33. Ceriani, R. L., Sasaki, M., Sussman, H., Wara, W. M., and Blank, E. W. (1982) Proc. Natl. Acad. Sci. U.S.A. 79, 54205424.

34. Reutelingsperger, C. P., and van Heerde, W. L. (1997) Cell Mol. Life Sci. 53, 527-532.

35. Collins, C., Nehlin, J. O., Stubbs, J., Kowbel, D., Kuo, W., and Parry, G. (1997) Genomics 39, 117-118.

36. Huang, S., Endo, R. I., and Nemerow, G. R. (1995) J. Virol. 69, 2257-2263.

37. Faull, R. J., and Stavros, W. (1996) Nephrol. Dial. Transplant. $11,2037-2044$

38. Théry, C., Regnault, A., Garin, J., Wolfers, J., Zitvogel, L., Ricciardi-Castagnoli, P., Raposo, G., and Amigorena, S. (1999) J. Cell Biol. 147, 599-610.

BI992221R 